The University of San Francisco

USF Scholarship: a digital repository@ Gleeson Library |

Geschke Center

2003

\title{
Anion Photoelectron Spectroscopy of Solvated Transition State Precursors
}

Harry Gomez

Giovanni Meloni

University of San Francisco, gmeloni@usfca.edu

James Madrid

D M. Neumark

Follow this and additional works at: http://repository.usfca.edu/chem_fac

Part of the Chemistry Commons

\section{Recommended Citation}

Gómez, Harry; Meloni, Giovanni; Madrid, James; Neumark, Daniel M. Anion Photoelectron Spectroscopy of Solvated Transition State Precursors. Journal of Chemical Physics. 7/8/2003, Vol. 119 Issue 2, p872.

This Article is brought to you for free and open access by the Chemistry at USF Scholarship: a digital repository @ Gleeson Library| Geschke Center. It has been accepted for inclusion in Chemistry Faculty Publications by an authorized administrator of USF Scholarship: a digital repository @ Gleeson Library $\mid$ Geschke Center. For more information, please contact repository@usfca.edu. 


\title{
Anion photoelectron spectroscopy of solvated transition state precursors
}

\author{
Harry Gómez, Giovanni Meloni, James Madrid, and Daniel M. Neumark \\ Department of Chemistry, University of California, Berkeley, California 94720 and Chemical Sciences \\ Division, Lawrence Berkeley National Laboratory, Berkeley, California 94720
}

(Received 14 February 2003; accepted 4 April 2003)

\begin{abstract}
Photoelectron (PE) spectra have been collected for the clustered bihalide anions $\mathrm{XHX}^{-} \cdot(\mathrm{M})(\mathrm{X}=\mathrm{Br}$, I) and $\mathrm{BrHI}^{-} \cdot(\mathrm{M})$, where $\mathrm{M}=\mathrm{H}_{2} \mathrm{O}, \mathrm{HBr}$, and $\mathrm{HI}$, in order to probe the effects of strongly solvating species on the PE spectra of transition state precursor anions. The PE spectra of the $\mathrm{XHX}^{-} \cdot\left(\mathrm{H}_{2} \mathrm{O}\right)$ ions show similar vibrational progressions as the spectra of the bare $\mathrm{BrHBr}^{-}$and $\mathrm{IHI}^{-}$anions, indicating that photodetachment of the bare and hydrated ions accesses similar XHX transition state geometries on the $\mathrm{X}+\mathrm{HX}$ reaction potential energy surfaces. These results are consistent with electronic structure calculations that predict a double hydrogen-bonded $\mathrm{XHX}^{-} \cdot\left(\mathrm{H}_{2} \mathrm{O}\right)$ structure in which the symmetry of the strong $\mathrm{XHX}^{-}$hydrogen bond is largely preserved. In contrast, $\mathrm{PE}$ spectra of $\mathrm{BrHBr}^{-}(\mathrm{HBr})_{1,2}$ and $\mathrm{IHI}^{-}(\mathrm{HI})_{1,2}$ indicate that the addition of a single $\mathrm{HBr}$ or $\mathrm{HI}$ disrupts the symmetric $\mathrm{XHX}^{-}$bond, resulting in structures of the form $\mathrm{X}^{-} \bullet(\mathrm{HX})_{n}$, and altering the geometry of the Franck-Condon region accessed on the neutral potential energy surfaces. Similarly, PE spectra of $\mathrm{BrHI}^{-} \bullet(\mathrm{HI})$ and $\mathrm{BrHI}^{-} \bullet(\mathrm{HBr})$ suggest anion structures of the form $\mathrm{I}^{-} \bullet(\mathrm{HBr}) \mathrm{HI}$ and $\mathrm{I}^{-} \bullet(\mathrm{HBr})_{2}$, respectively. (C) 2003 American Institute of Physics. [DOI: 10.1063/1.1577331]
\end{abstract}

\section{INTRODUCTION}

The transition state region of a chemical reaction is of fundamental importance in chemical reaction dynamics. During the past $10-15$ years, there have been numerous experimental and theoretical studies on transition state spectroscopy of isolated gas phase reactions, yielding new insights into the nature of the reaction potential energy surface near the transition state and the reaction dynamics that occur in this region of the surface. ${ }^{1-5}$ These experiments raise the fundamentally interesting question of how transition state spectroscopy and dynamics would differ in a condensed phase environment. ${ }^{6,7}$ This question can be addressed systematically by initiating transition state dynamics in sizeselected clusters in which the reacting species are complexed to a known number of solvent atoms or molecules. Studies of this type are presented here, in which photoelectron (PE) spectroscopy of clustered transition state precursor anions is used to probe the effect of solvation on anion structure and on the neutral transition state.

We have previously shown that PE spectroscopy of stable negative ions can be used to study transition state species for gas phase bimolecular chemical reactions. ${ }^{5}$ The reactions studied include several heavy+light-heavy hydrogen transfer systems such as the $\mathrm{I}+\mathrm{HI}, \mathrm{Br}+\mathrm{HBr}$, and $\mathrm{Br}+\mathrm{HI}$ reactions, ${ }^{8-11}$ as well as the benchmark $\mathrm{F}+\mathrm{H}_{2}$ and $\mathrm{OH}+\mathrm{H}_{2}$ reactions. ${ }^{12-14}$ In these experiments, the PE spectrum is collected for anions such as $\mathrm{IHI}^{-}, \mathrm{FH}_{2}^{-}$, etc., whose geometry is very similar to that of transition state species on the neutral potential energy surface. The region of the potential energy surface which is studied by photodetachment of this "precursor anion" is determined by the Franck-Condon overlap between the anion and the neutral reaction surface. Even though the neutral species dissociate to either reactants or products, the PE spectra yield resolved structure associated with vibrational motion in the neutral transition state region perpendicular to the reaction coordinate, for example, the antisymmetric $\mathrm{H}$-atom stretching vibration in the IHI, $\mathrm{BrHBr}$, and $\mathrm{BrHI}$ neutral complexes. The higher resolution zero electron kinetic energy (ZEKE) spectrum of $\mathrm{IHI}^{-}$revealed additional features assigned to the IHI symmetric stretch vibration, associated with reactive resonances in the transition state, and to IHI hindered rotor progressions. ${ }^{9}$

The effects of weakly interacting solvent species on the PE spectra of transition state precursor anions were investigated by Arnold et al. ${ }^{15,16}$ who measured the PE spectra of $\mathrm{IHI}^{-}$and $\mathrm{IDI}^{-}$clustered with multiple $\mathrm{N}_{2} \mathrm{O}$ and $\mathrm{CO}_{2}$ molecules, and by Liu et al. ${ }^{17,18}$ who obtained PE spectra for $\mathrm{BrHI}^{-} \cdot \mathrm{Ar}$ and $\mathrm{IHI}^{-} \bullet(\mathrm{Ar})_{n=1-15}$. In all of these studies, the vibrational structure seen in the PE spectrum of the bare ion was preserved; the main effect of solvation was a shift of the photoelectron spectrum toward lower electron kinetic energy (eKE) because of stronger binding of the solvent species to the anion than the neutral. The PE spectra of $\mathrm{IHI}^{-} \cdot \mathrm{Ar}$ and $\mathrm{BrHI}^{-} \cdot \mathrm{Ar}$ were narrower than those of the bare ions, and the $\mathrm{IHI}^{-} \cdot$ Ar spectrum showed additional features that were not resolved in the $\mathrm{IHI}^{-}$PE spectrum (although most of them were seen in the ZEKE spectrum). These effects were attributed to the reduced contribution of vibrational hot bands in the PE spectra of the binary cluster ions; similar effects have been observed in the infrared (IR) spectra of clustered anions. ${ }^{19}$ In addition, PE spectra of the larger $\mathrm{IHI}^{-} \cdot(\mathrm{Ar})_{n}$ clusters showed more pronounced hindered rotor progressions than were seen in the smaller clusters, an effect attributed to an increased lifetime of the IHI complex in the larger clusters from "caging" by the Ar atoms. ${ }^{5}$

In the present work, we use anion PE spectroscopy to investigate the effects of more strongly solvating species, namely, $\mathrm{H}_{2} \mathrm{O}, \mathrm{HBr}$, and $\mathrm{HI}$, on the transition state precursor anions $\mathrm{BrHBr}^{-}, \mathrm{IHI}^{-}$, and $\mathrm{BrHI}^{-}$. These solvating species 
should bind much more strongly to the precursor anions, possibly inducing significant structural changes which must be understood if one hopes to interpret the effects of solvation on neutral TS dynamics. For example, structural changes in the transition state precursor will shift the Franck-Condon region of the neutral surface accessed by photodetachment, enabling one to probe regions of the reaction surface that are inaccessible from the bare ion. The PE spectra presented here are complementary to recent anion IR spectroscopy studies (using a free electron laser) of bare and complexed $\mathrm{BrHBr}^{-}$ by Pivonka et al..$^{20,21}$ that suggested that the addition of $\mathrm{HBr}$ molecules to $\mathrm{BrHBr}^{-}$breaks the $D_{\infty h}$ symmetry of the bihalide anion. The IR spectra in conjunction with electronic structure calculations indicated that only one solvent molecule $(\mathrm{HBr})$ is required to produce this effect, resulting in clusters of the form $\mathrm{Br}^{-} \cdot(\mathrm{HBr})_{n}$. In this work, we show how vibrational features in the PE spectra of the clustered bihalide ions reveal the extent of structural perturbations brought about by clustering.

\section{EXPERIMENT}

The negative ion time-of-flight (TOF) photoelectron spectrometer used in this study has been described in detail previously ${ }^{10,22}$ and only relevant details will be given here. $\mathrm{BrHBr}^{-} \bullet(\mathrm{HBr})_{n}, \mathrm{IHI}^{-} \bullet(\mathrm{HI})_{n}$, and $\mathrm{BrHI}^{-} \bullet(\mathrm{HX}) \quad(\mathrm{X}=\mathrm{Br}, \mathrm{I})$ clusters are prepared by coexpanding 4-40 psi of a $\mathrm{HBr}$ and/or HI argon mixture at room temperature through a pulsed molecular beam valve with a $\sim 0.25 \mathrm{~mm}$ diam orifice. The concentrations of $\mathrm{HBr}$ and/or HI are modified depending on the size of the clusters of interest. Typical concentrations range from 0.01 to $1.0 \% \mathrm{HI} / \mathrm{HBr}$ in argon. Water-containing clusters are generated by adding couple of drops of distilled water to the gas lines. Negative ions are generated by a 1 $\mathrm{keV}, 300 \mathrm{~mA}$ electron beam that crosses the gas jet just downstream of the nozzle, in the continuum flow region of the expansion. The ions are extracted perpendicularly to the expansion by means of a pulsed electric field into a linear reflection TOF mass spectrometer at an average beam energy of $2.5 \mathrm{keV}$. The mass resolution is $m / \Delta m=2000$. At the spatial focus of the mass spectrometer, ions are intersected and photodetached by a fixed frequency laser pulse from a $\mathrm{Nd}$ :YAG laser running at $20 \mathrm{~Hz}$. The fifth harmonic of the $\mathrm{Nd}$ :YAG laser at $213 \mathrm{~nm}(5.821 \mathrm{eV})$ was used in this study.

Photodetached electrons are detected at the end of a $1 \mathrm{~m}$ magnetically shielded flight tube, mounted orthogonally to the laser and ion beam, and are energy-analyzed by TOF. The instrumental resolution is $8-10 \mathrm{meV}$ for an electron kinetic energy (eKE) of $0.65 \mathrm{eV}$ and degrades as $(\mathrm{eKE})^{3 / 2}$. Approximately $25 \%$ of the ions are photodetached at $213 \mathrm{~nm}$ and about one electron is detected per laser shot. A typical spectrum requires 300 000-600 000 laser shots. Ultraviolet photons efficiently eject electrons from metal surfaces, resulting in a residual background photoelectron contribution of typically one electron per ten laser shots at $213 \mathrm{~nm}$, primarily at low eKE. Background spectra were recorded on a daily basis, summed, and then subtracted from the acquired data.

All PE spectra presented here are plotted as a function of the electron kinetic energy. In the PE spectra the eKE is

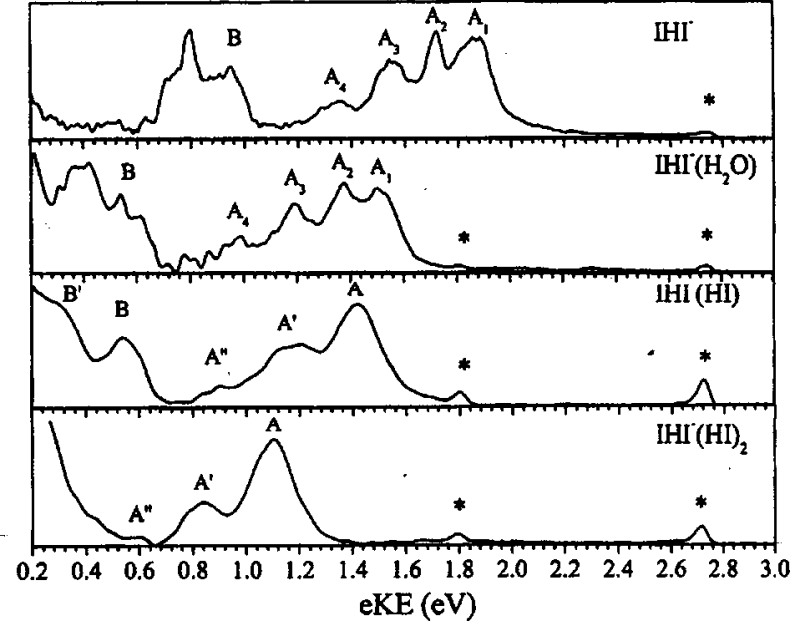

FIG. 1. Anion PE spectra of $\mathrm{IHI}^{-}$, $\mathrm{IHI}^{-} \bullet\left(\mathrm{H}_{2} \mathrm{O}\right)$, and $\mathrm{IHI}^{-} \bullet(\mathrm{HI})_{1,2}$ measured at a photon energy of $5.821 \mathrm{eV}(213 \mathrm{~nm})$.

related to the internal energy of the anion and neutral complex by

$$
\mathrm{eKE}=h \nu-\mathrm{EA}-T_{0}-E_{v}^{0}+E_{v}^{-} .
$$

In Eq. (1), $h \nu$ is the photon energy of the detachment laser, EA is the electron affinity of the complex, and $T_{0}$ is the term value for various electronic states. $E_{v}^{0}$ and $E_{v}^{-}$represent the vibrational energy of the neutral and anion complex, respectively. The angle between the laser polarization and the direction of electron collection can be varied by means of a half-wave plate. All spectra reported here were measured at a laser polarization angle of $90^{\circ}$.

\section{RESULTS}

\section{A. Photoelectron spectra}

The PE spectra of $\mathrm{XHX}^{-} \bullet\left(\mathrm{H}_{2} \mathrm{O}\right)$, and $\mathrm{XHX}^{-} \cdot(\mathrm{HX})_{1,2}(\mathrm{X}$ $=\mathrm{Br}, \mathrm{I})$ collected at $h \nu=5.821 \mathrm{eV}$ are shown in Figs. 1 and 2 along with the spectra of $\mathrm{IHI}^{-}$and $\mathrm{BrHBr}^{-}$. Figure 3 shows the photoelectron spectra of $\mathrm{BrHI}^{-} \cdot(\mathrm{HBr})$ and $\mathrm{BrHI}^{-} \cdot(\mathrm{HI})$

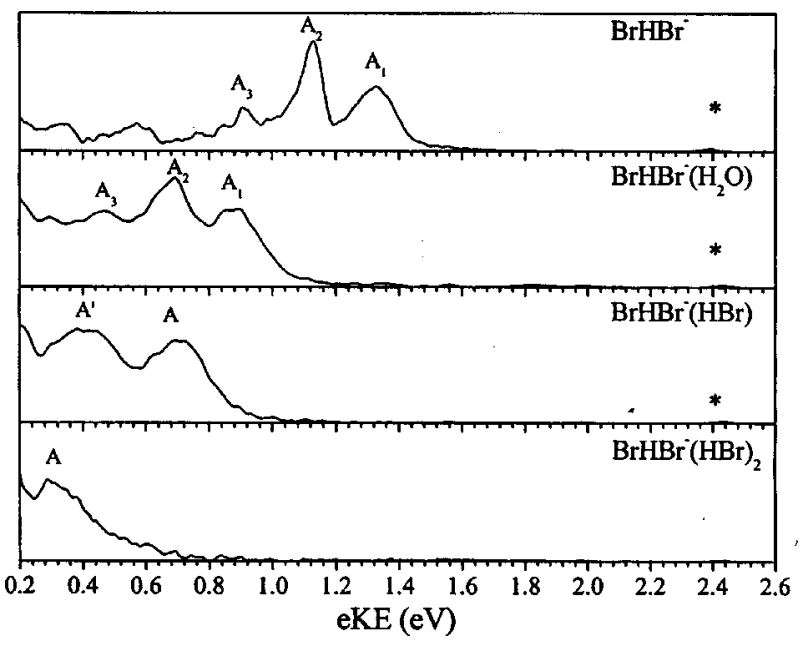

FIG. 2. Anion PE spectra of $\mathrm{BrHBr}^{-}, \mathrm{BrHBr}^{-} \bullet\left(\mathrm{H}_{2} \mathrm{O}\right)$, and $\mathrm{BrHBr}^{-} \cdot(\mathrm{HBr})_{1,2}$ measured at photon energy of $5.821 \mathrm{eV}(213 \mathrm{~nm})$. 


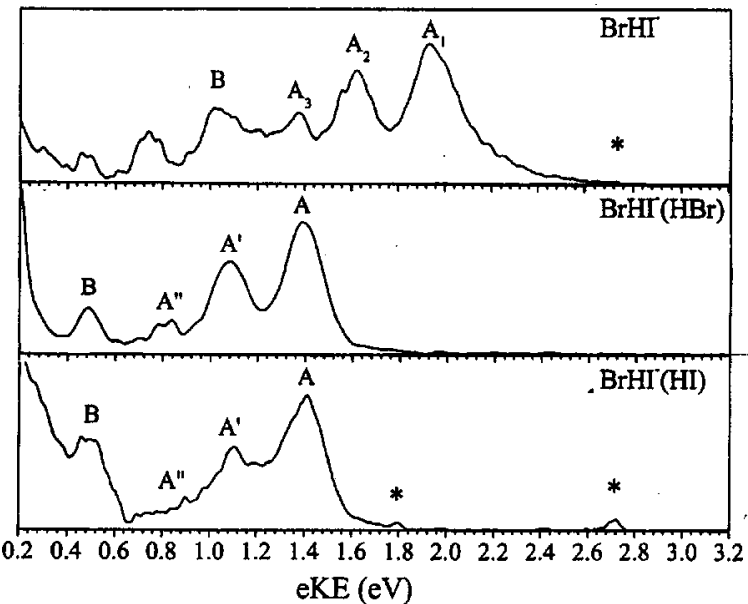

FIG. 3. Anion PE spectra of $\mathrm{BrHI}^{-}, \mathrm{BrHI}^{-} \cdot(\mathrm{HBr})$, and $\mathrm{BrHI}^{-} \cdot(\mathrm{HI})$ measured at a photon energy of $5.821 \mathrm{eV}(213 \mathrm{~nm})$.

along with the spectrum of bare $\mathrm{BrHI}^{-}$. Peak positions for each spectrum are given in Table I. The bare $\mathrm{BrHBr}^{-}, \mathrm{IHI}^{-}$, and $\mathrm{BrHI}^{-}$spectra at $h \nu=5.821 \mathrm{eV}$ are similar to those reported previously. ${ }^{8,10,11,23}$ The main vibrational progressions of $\mathrm{IHI}^{-}\left(A_{1}, A_{2}, A_{3}\right)$ and $\mathrm{BrHBr}^{-}\left(A_{1}, A_{2}, A_{3}\right)$ were attributed to the antisymmetric hydrogen vibrational stretch $\left(\nu_{3}\right)$ of the unstable neutral XHX complex with the vibrational assignment $\nu_{3}^{\prime}=0,2$, and 4 . The progression $A_{1}, A_{2}, A_{3}$ in $\mathrm{BrHI}^{-}$results from the same vibrational mode $\left(\nu_{3}\right)$ but with a slightly different vibrational assignment $\left(\nu_{3}^{\prime}=0,1\right.$, and 3 ), and corresponding to hydrogen vibrational motion more localized in the $\mathrm{I}+\mathrm{HBr}$ valley of the neutral surface. ${ }^{11}$ For $\mathrm{IHI}^{-}$and $\mathrm{BrHI}^{-}$, the peaks located at low electron kinetic energy $(B)$ are separated with respect to $A_{1}$ peaks by approximately the spin-orbit splitting of iodine $(0.943 \mathrm{eV}){ }^{24}$ In Figs. 1-3 peaks labeled as * at high electron kinetic energy correspond to photodetachment of bare halides $\left(\mathrm{X}^{-}\right)$. This signal is attributed to photodissociation followed by photodetachment of the atomic anion photofragment.

In general, the $\mathrm{IHI}^{-} \cdot\left(\mathrm{H}_{2} \mathrm{O}\right)$ and $\mathrm{BrHBr}^{-} \cdot\left(\mathrm{H}_{2} \mathrm{O}\right)$ spectra appear as broadened, shifted versions of the $\mathrm{IHI}^{-}$and $\mathrm{BrHBr}^{-}$spectra. The overall features of the spectra are similar to those of their corresponding bare ions. The peak spacing and relative intensities remain mostly unchanged for each complex compared with the bare ion. The $\mathrm{IHI}^{-} \cdot\left(\mathrm{H}_{2} \mathrm{O}\right)$ and $\mathrm{BrHBr}^{-} \cdot\left(\mathrm{H}_{2} \mathrm{O}\right)$ spectra are shifted to lower eKE compared to $\mathrm{IHI}^{-}$and $\mathrm{BrHBr}^{-}$by $355 \pm 20 \mathrm{meV}$ and $455 \pm 20$ $\mathrm{meV}$, respectively (using peaks $A_{1}$ on each spectrum).

In contrast, photoelectron spectra of species solvated by $\mathrm{HI}$ or $\mathrm{HBr}$ show a noticeably different envelope than the corresponding bare ions, exhibiting fewer and broader peaks that are more widely spaced than in the bare ion PE spectra. The peaks are shifted by $430 \pm 20 \mathrm{meV}, 745 \pm 20 \mathrm{meV}$, and $625 \pm 20 \mathrm{meV}$ for $\mathrm{IHI}^{-} \bullet(\mathrm{HI}), \quad \mathrm{IHI}^{-} \bullet(\mathrm{HI})_{2}, \quad$ and $\mathrm{BrHBr}^{-} \cdot(\mathrm{HBr})$, respectively (from peaks $A_{1}$ and $A$ ). While the $\mathrm{IHI}^{-}$peak spacings are $A_{1}-A_{2}=\sim 1300 \mathrm{~cm}^{-1}, A_{2}-A_{3}$ $=\sim 1400 \mathrm{~cm}^{-1}$, and $A_{3}-A_{4}=\sim 1550 \mathrm{~cm}^{-1}$, the peak spacings for $\mathrm{IHI}^{-} \cdot(\mathrm{HI})_{1,2}$ are $A-A^{\prime}=\sim 2200 \mathrm{~cm}^{-1}$ and $A^{\prime}-A^{\prime \prime}$ $=2200 \mathrm{~cm}^{-1}$, quite close to the vibrational frequency of $2230 \mathrm{~cm}^{-1}$ in diatomic HI. The $A-B$ separation for $\mathrm{IHI}^{-} \cdot(\mathrm{HI})$ spectrum is $0.901 \pm 0.030 \mathrm{eV}$, similar to that in bare $\mathrm{IHI}^{-}$. The $\mathrm{BrHBr}^{-}$peak spacings are $A_{1}-A_{2}=1550$ $\mathrm{cm}^{-1}$ and $A_{2}-A_{3}=1700 \mathrm{~cm}^{-1}$, while the peak spacing for $\mathrm{BrHBr}^{-} \cdot(\mathrm{HBr})$ is $A-A^{\prime}=\sim 2400 \mathrm{~cm}^{-1}$, close to but slightly smaller than the diatomic $\mathrm{HBr}$ vibrational frequency, 2558 $\mathrm{cm}^{-1}$. For $\mathrm{BrHBr}^{-} \cdot(\mathrm{HBr})_{2}$, only one peak is accessible at $213 \mathrm{~nm}$ due to the large shift to lower eKE following the addition of an additional $\mathrm{HBr}$.

The $\mathrm{BrHI}^{-} \bullet(\mathrm{HI})$ and $\mathrm{BrHI}^{-} \bullet(\mathrm{HBr})$ spectra shown in Fig. 3 are quite similar. Both spectra are shifted by approximately $540 \mathrm{meV}$ with respect to $\mathrm{BrHI}^{-}$, also shown in Fig. 3 (from peaks $A_{1}$ and $A$ ). Both cluster PE spectra show a vibrational progression of around $\sim 2500 \mathrm{~cm}^{-1}$, essentially the same as for the bare $\mathrm{BrHI}^{-}$, although the progressions are somewhat less extended in the clustered ions. The $\mathrm{BrHI}^{-} \bullet(\mathrm{HBr})$ progression is less congested than that for $\mathrm{BrHI}^{-} \cdot(\mathrm{HI})$. The $A-B$ separation in all three spectra in Fig. 3 is $0.920 \pm 0.030$ $\mathrm{eV}$, again close to the spin-orbit splitting in atomic iodine.

\section{B. Electronic structure calculations}

Electronic structure calculations were performed to assist in the interpretation of the data presented above. These calculations are aimed at determining the geometries of the solvated complexes. Geometries were optimized at the HF and UHF (unrestricted Hartree-Fock) levels of theory for the anion and neutral, respectively, then further explored

TABLE I. Experimental peaks position and labels.

\begin{tabular}{ll}
\hline \hline \multicolumn{1}{c}{ Species } & \multicolumn{1}{c}{ Position $(\mathrm{eV})^{\mathrm{a}}$} \\
\hline $\mathrm{IHI}^{-}$ & $1.879\left(A_{1}\right), 1.719\left(A_{2}\right), 1.545\left(A_{3}\right), 1.353\left(A_{4}\right), 0.940(B)$ \\
$\mathrm{IHI}^{-} \cdot\left(\mathrm{H}_{2} \mathrm{O}\right)$ & $1.502\left(A_{1}\right), 1.375\left(A_{2}\right), 1.187\left(A_{3}\right), 0.982\left(A_{4}\right), 0.530(B)$ \\
$\mathrm{IHI}^{-} \cdot(\mathrm{HI})$ & $1.425(A), 1.160\left(A^{\prime}\right), 0.899\left(A^{\prime \prime}\right), 0.522(B)$ \\
$\mathrm{IHI}^{-} \cdot(\mathrm{HI})_{2}$ & $1.099(A), 0.835\left(A^{\prime}\right), 0.584\left(A^{\prime \prime}\right)$ \\
$\mathrm{BrHBr}^{-}$ & $1.327\left(A_{1}\right), 1.125\left(A_{2}\right), 0.914\left(A_{3}\right)$ \\
$\mathrm{BrHBr}^{-} \cdot\left(\mathrm{H}_{2} \mathrm{O}\right)$ & $0.872\left(A_{1}\right), 0.680\left(A_{2}\right), 0.465\left(A_{3}\right)$ \\
$\mathrm{BrHBr}^{-} \cdot(\mathrm{HBr})$ & $0.693(A), 0.397\left(A^{\prime}\right)$ \\
$\mathrm{BrHBr}^{-} \cdot(\mathrm{HBr})_{2}$ & $0.306(A)$ \\
$\mathrm{BrHI}^{-}$ & $1.935\left(A_{1}\right), 1.615\left(A_{2}\right), 1.365\left(A_{3}\right), 1.045\left(B_{1}\right), 0.739\left(B_{2}\right), 0.473\left(B_{3}\right)$ \\
$\mathrm{BrHI}^{-} \cdot(\mathrm{HBr})$ & $1.391(A), 1.081\left(A^{\prime}\right), 0.817\left(A^{\prime \prime}\right), 0.485(B)$ \\
$\mathrm{BrHI}^{-} \cdot(\mathrm{HI})$ & $1.409(A), 1.103\left(A^{\prime}\right), 0.846\left(A^{\prime \prime}\right), 0.502(B)$ \\
\hline
\end{tabular}

${ }^{\mathrm{a}}$ Error $\pm 0.025 \mathrm{eV}$. 
TABLE II. Results of DFT electronic structure calculations for $\mathrm{XHX}^{-}$, $\mathrm{H}_{2} \mathrm{O}, \mathrm{HBr}$, and $\mathrm{HI}$. All bond lengths are in $\AA$, angles in deg, and vibrational frequencies in $\mathrm{cm}^{-1}$.

\begin{tabular}{|c|c|c|c|c|}
\hline Species & Method & $A_{\mathrm{X}-\mathrm{H}-\mathrm{X}}$ & $R_{\mathrm{X}-\mathrm{H}}$ & Frequencies \\
\hline \multirow[t]{2}{*}{$\mathrm{IHI}^{-}$} & $D_{\infty h} \mathrm{~B} 3 \mathrm{LYP} / 3-21 \mathrm{G}^{* *}$ & 180.0 & 1.984 & $\begin{array}{lll}132 & 575 & 1079\end{array}$ \\
\hline & B3LYP/6-311G** & 180.0 & 1.954 & 141601906 \\
\hline \multirow[t]{2}{*}{$\mathrm{BrHBr}^{-}$} & $D_{\infty h}$ B3LYP/6-311++G** & 180.0 & 1.731 & 198700801 \\
\hline & B3LYP/aug-cc-pVDZ & 180.0 & 1.729 & 197703829 \\
\hline \multirow[t]{2}{*}{$\mathrm{BrHI}^{-}$} & $D_{\infty h} \mathrm{~B} 3 \mathrm{LYP} / 6-311 \mathrm{G}^{* *}$ & 180.0 & $\begin{array}{l}1.580^{\mathrm{a}} \\
2.176^{\mathrm{b}}\end{array}$ & $\begin{array}{lll}133 & 595 & 1309\end{array}$ \\
\hline & & $A_{\mathrm{H}-\mathrm{O}-\mathrm{H}}$ & $R_{\mathrm{O}-\mathrm{H}}$ & Frequencies \\
\hline
\end{tabular}

$\begin{array}{cclllll}\mathrm{H}_{2} \mathrm{O} \quad C_{2 V} & \text { B3LYP/6-311++ } \mathrm{G}^{* *} & 105.0 & 0.962 & 1602 & 3815 & 3920 \\ & \text { B3LYP/aug-cc-pVDZ } & 104.7 & 0.965 & 1614 & 3801 & 3906 \\ \text { Experiment }^{c} & 104.5 & 0.965 & 1595 & 3755 & 3656 \\ & & R_{\mathrm{O}-\mathrm{H}} & \text { Frequency } & & & \\ & & \end{array}$

\begin{tabular}{lcll}
$\mathrm{HBr} \quad C_{\infty h}$ B3LYP/6-311++G* & 1.427 & 2593 \\
& B3LYP/aug-cc-pVDZ & 1.431 & 2595 \\
& Experiment & \\
$\mathrm{HI}$ & $C_{\infty h}$ & 1.414 & $2648.97^{\mathrm{e}}$ \\
& B3LYP/3-21G** & 1.639 & 2308 \\
& B3LYP/6-311G** & 1.626 & 2337 \\
& Experiment $^{\mathrm{d}}$ & 1.609 & $2309.01^{\mathrm{e}}$ \\
\hline
\end{tabular}

This is $R_{\mathrm{Br}-\mathrm{H}}$. $\quad{ }^{\mathrm{d}}$ From Ref. 39.

${ }^{\mathrm{b}} \mathrm{This}$ is $R_{\mathrm{I}-\mathrm{H}}$. $\quad{ }^{\mathrm{e}}$ Harmonic frequency.

${ }^{\mathrm{c}}$ From Ref. 38.

using density functional theory (DFT) with the B3LYP (Becke-3-parameter-Lee-Yang-Parr) exchange correlation functional. ${ }^{25,26}$ The STO-3G* $, 3-21 \mathrm{G}^{* *}, 6-311 \mathrm{G}^{* *}$, and aug-cc-pVDZ basis sets were used during the study. However, for iodine-containing clusters the biggest basis set used is $6-311 \mathrm{G}^{* *}$. Calculations were performed using the GAUSSIAN 98 electronic structure package, ${ }^{27}$ and the results are summarized in Tables II-V. Calculated anion structures are shown in Fig. 4. Experimental and $a b$ initio results for $\mathrm{H}_{2} \mathrm{O}, \mathrm{HI}$, and $\mathrm{HBr}$ are included in Table II for comparison.

\section{C. $\mathrm{XHX}^{-} \cdot\left(\mathrm{H}_{2} \mathrm{O}\right)$}

Several configurations for the $\mathrm{XHX}^{-} \cdot\left(\mathrm{H}_{2} \mathrm{O}\right)$ clusters were explored at the HF and B3LYP level of theory. As starting geometries, we used singly and doubly hydrogen-bonded structures similar to those found for $\mathrm{FHF}^{-} \bullet\left(\mathrm{H}_{2} \mathrm{O}\right)$ by $\mathrm{Li}$ et $a{ }^{28}$ All single hydrogen-bonded configurations have the excess charge partially localized on one halogen with the water molecule bound to that halogen, i.e., $\mathrm{XH}^{\cdots} \cdot \mathrm{X}^{-} \cdot \mathrm{H}_{2} \mathrm{O}$.
In these configurations, which have overall $C_{s}$ symmetry, the symmetries of both the $\mathrm{XHX}^{-}\left(D_{\infty h}\right)$ anion and water molecule $\left(C_{2 v}\right)$ are broken. The double hydrogen-bonded structures exhibit $C_{2 v}$ symmetry where each water hydrogen is bonded to one halogen. At the highest level of theory, the lowest energy structures for $\mathrm{BrHBr}^{-} \bullet\left(\mathrm{H}_{2} \mathrm{O}\right)$ and $\mathrm{IHI}^{-} \bullet\left(\mathrm{H}_{2} \mathrm{O}\right)$ were found to be the double hydrogen-bonded complexes shown in Fig. 4(A). The lowest energy $C_{s}$ configurations, similar to the equilibrium structure TSI by Li et al. ${ }^{28}$ shown in Fig. 4(B), lie approximately $0.1 \mathrm{eV}$ higher than structure A for $\mathrm{BrHBr}^{-} \bullet\left(\mathrm{H}_{2} \mathrm{O}\right)$ and $\mathrm{IHI}^{-} \bullet\left(\mathrm{H}_{2} \mathrm{O}\right)$. According to our computations, this structure has an imaginary frequency. Two other $C_{s}$ starting geometries, similar to the equilibrium structures EQU and TSII by Li et al., ${ }^{28}$ converged to the $C_{2 v}$ structure. Bond lengths and angles for the $\mathrm{XHX}^{-} \cdot\left(\mathrm{H}_{2} \mathrm{O}\right)$ complex computed at the B3LYP level of theory using different basis sets are summarized in Table III.

Vibrational analysis of the $C_{2 v}$ structures reveals no imaginary frequencies, showing that these are minima and not transition states. The water molecule binds to both the halogen atoms equally, and the charge of the complex is shared equally between the halogen atoms. The attraction in the complex is strong enough to cause small changes in the water and $\mathrm{XHX}^{-}$molecules. The $\mathrm{XHX}^{-}$bond angle changes from $180^{\circ}$ in the bare ion to about $177^{\circ}$ for both $\mathrm{IHI}^{-}$and $\mathrm{BrHBr}^{-}$with the largest basis set. The bond angle for the water molecule drops from $104.5^{\circ}$ to about $102^{\circ}$ for both anions. The $\mathrm{HX}$ and $\mathrm{OH}$ bond lengths in the clusters are very similar to the calculated values for bare $\mathrm{XHX}^{-}$and $\mathrm{H}_{2} \mathrm{O}$ in Table II.

Our results are slightly different than those reported by Li et $a .^{28}$ on $\mathrm{FHF}^{-} \cdot\left(\mathrm{H}_{2} \mathrm{O}\right)$. They found a single hydrogenbonded $C_{s}$ structure to be the minimum, and the double hydrogen-bonded $C_{2 v}$ structure to be either a transition state or local minimum, depending on the level of theory. However, the energy differences among these structures were very small $(<1 \mathrm{meV}$ at the highest level of theory used in their calculation) indicating a relatively flat potential energy landscape. The $C_{2 v}$ geometry found by us to be the global minimum for $\mathrm{BrHBr}^{-} \bullet\left(\mathrm{H}_{2} \mathrm{O}\right)$ and $\mathrm{IHI}^{-} \bullet\left(\mathrm{H}_{2} \mathrm{O}\right)$ is favored by the presence of two hydrogen bonds, and involves less of a perturbation of the $\mathrm{H}-\mathrm{O}-\mathrm{H}$ bond angle in free water compared to $\mathrm{FHF}^{-} \cdot\left(\mathrm{H}_{2} \mathrm{O}\right)$. A similar double hydrogen-bond has been proposed by Johnson and co-workers ${ }^{29}$ to explain the infrared spectrum of $\mathrm{SO}_{2}^{-} \bullet\left(\mathrm{H}_{2} \mathrm{O}\right)$.

Finally, we calculated the binding energy $(\mathrm{BE})$ of the

TABLE III. Results of DFT electronic structure calculations for $\mathrm{XHX}^{-} \cdot\left(\mathrm{H}_{2} \mathrm{O}\right)$ clusters. All bond lengths are in $\AA$ and angles in deg.

\begin{tabular}{|c|c|c|c|c|c|c|c|c|}
\hline Species & & Method & $A_{\mathrm{X}-\mathrm{H}-\mathrm{X}}$ & $R_{\mathrm{H} \cdots \mathrm{X}}$ & $R_{\mathrm{H}-\mathrm{X}}$ & $R_{\mathrm{O}-\mathrm{H}}$ & $A_{\mathrm{H}-\mathrm{O}-\mathrm{H}}$ & $A_{\mathrm{H}-\mathrm{X} \cdots \mathrm{H}}$ \\
\hline \multirow[t]{2}{*}{$\mathrm{IHI}^{-} \bullet\left(\mathrm{H}_{2} \mathrm{O}\right)$} & \multirow[t]{2}{*}{$C_{2 V}$} & B3LYP/3-21G** & 175.8 & 2.873 & 1.947 & 0.970 & 101.2 & 67.5 \\
\hline & & B3LYP/6-311G** & 177.1 & 2.973 & 1.950 & 0.971 & 102.0 & 67.7 \\
\hline \multirow{6}{*}{$\mathrm{BrHBr}^{-} \bullet\left(\mathrm{H}_{2} \mathrm{O}\right)$} & \multirow{2}{*}{$C_{2 V}$} & B3LYP/6-311+ + G** & 176.2 & 2.737 & 1.731 & 0.967 & 101.1 & 70.9 \\
\hline & & B3LYP/aug-cc-pvdz & 176.9 & 2.730 & 1.729 & 0.971 & 101.3 & 70.6 \\
\hline & \multirow[t]{4}{*}{$C s$} & B3LYP/6-311++G $\mathrm{G}^{* *}$ & 179.4 & 2.553 & 1.607 & 0.975 & 103.7 & \\
\hline & & & & & 1.906 & 0.963 & & \\
\hline & & B3LYP/aug-cc-pvdz & 179.1 & 2.487 & 1.611 & 0.979 & 102.0 & \\
\hline & & & & & 1.880 & 0.964 & & \\
\hline
\end{tabular}


TABLE IV. Results of DFT electronic structure calculations for $\mathrm{IHI}^{-} \bullet(\mathrm{HI})_{1,2}$ clusters. All bond lengths are in $\AA$ and angles in deg.

\begin{tabular}{|c|c|c|c|c|c|c|}
\hline Species & & Method & $A_{\mathrm{H} \cdots \mathrm{I} \cdots \mathrm{H}}$ & $R_{\mathrm{I}-\mathrm{H}}$ & $R_{\mathrm{I} \cdots \mathrm{H}}$ & $A_{\mathrm{I} \cdots \mathrm{H}-\mathrm{I}}$ \\
\hline \multirow[t]{2}{*}{$\mathrm{IHI}^{-} \bullet(\mathrm{HI})$} & \multirow{2}{*}{$C_{2 V}$} & B3LYP/3-21G** & 107.7 & 1.780 & 2.196 & 177.6 \\
\hline & & B3LYP/6-311G** & 107.6 & 1.753 & 2.254 & 177.7 \\
\hline Experiment $^{\mathrm{a}}$ & & & & 1.742 & & \\
\hline \multirow[t]{2}{*}{$\mathrm{IHI}^{-} \bullet(\mathrm{HI})_{2}$} & $C_{3 V}$ & B3LYP/3-21G** & 107.9 & 1.728 & 2.332 & 179.0 \\
\hline & & B3LYP/6-311G** & 108.1 & 1.698 & 2.414 & 179.5 \\
\hline Experiment $^{\mathrm{a}}$ & & & & 1.709 & & \\
\hline
\end{tabular}

${ }^{a}$ From Franck-Condon simulations in Fig. 6.

$\mathrm{H}_{2} \mathrm{O}$ to the bare ion using the relationship $\mathrm{BE}=E\left(\mathrm{XHX}^{-}\right)-\left[E\left(\mathrm{XHX}^{-} \cdot\left(\mathrm{H}_{2} \mathrm{O}\right)\right)-E\left(\mathrm{H}_{2} \mathrm{O}\right)\right], \quad$ where $E\left(\mathrm{XHX}^{-}\right), E\left(\mathrm{XHX}^{-} \cdot\left(\mathrm{H}_{2} \mathrm{O}\right)\right)$, and $E\left(\mathrm{H}_{2} \mathrm{O}\right)$ are the computed total energy of $\mathrm{XHX}^{-}, \mathrm{XHX}^{-} \bullet\left(\mathrm{H}_{2} \mathrm{O}\right)$, and $\mathrm{H}_{2} \mathrm{O}$. We obtained BE's of 0.42 and $0.39 \mathrm{eV}$ for $\mathrm{BrHBr}^{-} \cdot\left(\mathrm{H}_{2} \mathrm{O}\right)$ and $\mathrm{IHI}^{-} \bullet\left(\mathrm{H}_{2} \mathrm{O}\right)$, respectively. These values compare well with the experimental solvent shifts of 0.455 and $0.355 \mathrm{eV}$ for $\mathrm{BrHBr}^{-} \bullet\left(\mathrm{H}_{2} \mathrm{O}\right)$ and $\mathrm{IHI}^{-} \bullet\left(\mathrm{H}_{2} \mathrm{O}\right)$.

\section{D. $\mathrm{IHI}^{-} \cdot(\mathrm{HI})_{n}$}

The $\mathrm{IHI}^{-} \cdot(\mathrm{HI})_{n}$ structures share similar characteristics with experimental and theoretical results on clusters of the type $\mathrm{XHX}^{-} \cdot(\mathrm{HX})_{n}(\mathrm{X}=\mathrm{F}, \mathrm{Br})$ ions. $^{20,30,31}$ The lowest energy structures for $n=1$ and 2 are shown in Figs. 4(C)-4(D), and the geometries are given in Table IV. In contrast to the complex with $\mathrm{H}_{2} \mathrm{O}$, solvation by one or more $\mathrm{HI}$ molecules disrupts the symmetric hydrogen bond of $\mathrm{IHI}^{-}$, resulting in a structure better described as $\mathrm{I}^{-} \bullet(\mathrm{HI})_{n+1}$, in which $\mathrm{I}^{-}$is solvated by multiple $\mathrm{HI}$ molecules. For example, the $\mathrm{IHI}^{-} \bullet(\mathrm{HI})$ complex has a $C_{2 v}$ structure [Fig. $\left.4(\mathrm{C})\right]$ and population analysis reveals that more than $58 \%$ of the complex charge is located in the central halogen atom, indicating that the anion complex behaves more like a single halogen solvated by two $\mathrm{HI}\left[\right.$ i.e., $\left.\mathrm{I}^{-} \bullet(\mathrm{HI})_{2}\right]$. The $\mathrm{IHI}^{-} \bullet(\mathrm{HI})_{2}$ complex exhibits an ammonialike structure with $C_{3 v}$ symmetry [Fig. 4(D)]. This complex has an iodine center which carries most of the excess charge $(51 \%)$ analogous to $\mathrm{IHI}^{-} \bullet(\mathrm{HI})$, although in this case it is surrounded by three $\mathrm{HI}$ molecules $\left[\right.$ i.e., $\left.\mathrm{I}^{-} \bullet(\mathrm{HI})_{3}\right]$.

\section{E. $\mathrm{BrHI}^{-} \cdot(\mathrm{HX})$}

Results for $\mathrm{BrHI}^{-} \bullet(\mathrm{HX})$ clusters are summarized in Table V. The $\mathrm{BrHI}^{-} \bullet(\mathrm{HX})(\mathrm{X}=\mathrm{Br}, \mathrm{I})$ structures are similar to the $\mathrm{IHI}^{-} \cdot(\mathrm{HI})$ clusters. The calculations show that the charge is mostly localized in a central iodine atom resulting in complexes of the type $\mathrm{I}^{-} \cdot(\mathrm{HBr})_{2}$ and $\mathrm{I}^{-} \cdot(\mathrm{HBr})(\mathrm{HI})$. In $\mathrm{I}^{-} \cdot(\mathrm{HBr})_{2}$, the calculated $\mathrm{HBr}$ bond length at the $\mathrm{B} 3 \mathrm{LYP} / 6-311 \mathrm{G}^{* *}$ level of theory is $6 \%$ longer than diatomic $\mathrm{HBr}$ at the same level of theory, while the $\mathrm{HI}$ and $\mathrm{HBr}$ bond lengths in $\mathrm{I}^{-} \bullet(\mathrm{HBr})(\mathrm{HI})$ are longer than free $\mathrm{HI}$ and $\mathrm{HBr}$ by $9 \%$ and $6 \%$, respectively. In $\mathrm{I}^{-}(\mathrm{HBr})(\mathrm{HI})$, the $\mathrm{HI}$ molecule is significantly closer to the central iodine than $\mathrm{HBr}$, suggesting a stronger interaction between the central $\mathrm{I}^{-}$and the $\mathrm{HI}$, and consistent with the larger change in bond length in HI compared to $\mathrm{HBr}$.

\section{DISCUSSION}

The PE spectra in Figs. 1-3 show two effects attributed to solvation of the $\mathrm{XHX}^{-}$and $\mathrm{XHY}^{-}$anions. First, solvation by a water molecule or a HX species shifts the photoelectron spectrum to considerably lower eKE for all the systems reported here. On the other hand, the effect of solvation on vibrational structure is system-dependent. The $\mathrm{BrHBr}^{-} \cdot \mathrm{H}_{2} \mathrm{O}$ and $\mathrm{IHI}^{-} \cdot \mathrm{H}_{2} \mathrm{O}$ PE spectra show the same vibrational structure as the bare ions, and the same is true for the $\mathrm{BrHI}^{-} \cdot \mathrm{HX}$ $\mathrm{PE}$ spectra. The $\mathrm{PE}$ spectra of $\mathrm{BrHBr}^{-} \cdot(\mathrm{HBr})_{n}$ and $\mathrm{IHI}^{-} \bullet(\mathrm{HI})_{n}$ are quite different from those of the bare ions, with noticeably larger vibrational spacings that are very close to the diatomic HX frequencies.

The energetic shift upon clustering is the well-known "solvent shift" seen in negative ion photoelectron spectroscopy ${ }^{32}$ and reflects the stronger binding of the solvent to the charged anion than to the neutral species formed by photodetachment. The observed effects of clustering upon vibrational structure are more unusual. They reflect the degree of distortion in the $\mathrm{XHX}^{-}$and $\mathrm{XHY}^{-}$anions induced by solvation. If the bihalide chromophore is left relatively intact, then the PE spectrum will be similar to that of the bare ion (aside from the solvent shift), but if solvation produces a structural change, the PE spectrum will differ from that of the bare ion, because photodetachment will access a different region of the neutral potential energy surface. This interpretation is supported by the electronic structure calculations presented in Sec. III B. In the remainder of this section, individual PE spectra are analyzed and discussed with particular reference paid to the calculations.

TABLE V. Results of DFT electronic structure calculations for $\mathrm{BrHI}^{-} \cdot(\mathrm{HBr})$ and $\mathrm{BrHI}^{-} \cdot(\mathrm{HI})$ clusters. All bond lengths in $\AA$ and angles in deg.

\begin{tabular}{lccccccc}
\hline \hline \multicolumn{1}{c}{ Species } & & Method & $A_{\mathrm{H}-\mathrm{I}-\mathrm{H}}$ & $R_{\mathrm{I} \cdots \cdot \mathrm{HBr}}{ }^{\mathrm{a}}$ & $R_{\mathrm{I} \cdots \mathrm{HI}}{ }^{\mathrm{b}}$ & $R_{\mathrm{H}-\mathrm{Br}}$ & $R_{\mathrm{H}-\mathrm{I}}$ \\
\hline $\mathrm{BrHI}^{-} \cdot(\mathrm{HI})$ & $C_{S}$ & B3LYP/3-21G** & 110.2 & 2.344 & 2.135 & 1.505 & 1.810 \\
& & B3LYP/6-311G** & 110.6 & 2.387 & 2.198 & 1.498 & 1.773 \\
Experiment $^{\mathrm{c}}$ & & & & & & 1.477 & 1.678 \\
$\mathrm{BrHI}^{-} \cdot(\mathrm{HBr})$ & $C_{2 V}$ & B3LYP/3-21G** & 114.9 & 2.277 & & 1.524 & \\
& & B3LYP/6-311G** & 100.5 & 2.340 & & 1.512 & \\
Experiment $^{\mathrm{c}}$ & & & & & & 1.549 & \\
\hline
\end{tabular}

${ }^{\mathrm{a}} R_{\mathrm{I} \cdots \mathrm{HBr}}$ is the distance between the central I and the $\mathrm{H}$ of $\mathrm{HBr}$ [see Fig. 5(C)].

${ }^{\mathrm{b}} R_{\mathrm{I} \cdots \mathrm{HI}}$ is the distance between the central I and the $\mathrm{H}$ of $\mathrm{HI}$ [see Fig. 5(C)].

${ }^{c}$ From Franck-Condon simulation in Fig. 6. 


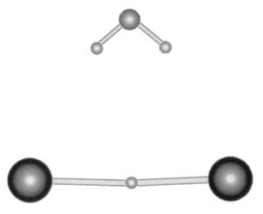

A

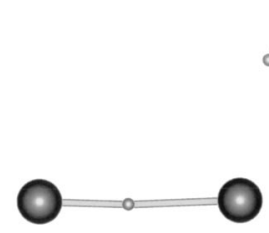

B

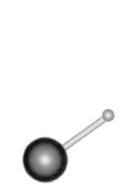

$\mathrm{C}$

C

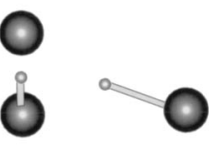

$\mathrm{D}$

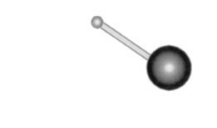

FIG. 4. Lowest energy structures calculated for the anions based on results from Tables III-V. For the $\mathrm{BrHI}^{-} \bullet(\mathrm{HBr})$ complex $(\mathrm{C})$ iodine occupies the center of the complex.

\section{A. $\mathrm{XHX}^{-} \cdot \mathrm{H}_{2} \mathrm{O}$}

The PE spectra of the $\mathrm{BrHBr}^{-} \cdot \mathrm{H}_{2} \mathrm{O}$ and $\mathrm{IHI}^{-} \cdot \mathrm{H}_{2} \mathrm{O}$ clusters in Figs. 1 and 2 show vibrational progressions with similar peak spacings and intensities as were seen in the spectra of $\mathrm{BrHBr}^{-}$and $\mathrm{IHI}^{-}$. This result indicates that photodetachment of the bare and hydrated anions accesses essentially the same region of the $\mathrm{X}+\mathrm{HX}$ potential energy surface, namely the XHX transition state region, so that the PE spectra in both cases are dominated by a progression in the $\nu_{3}$ antisymmetric stretch mode of the neutral XHX complex. Moreover, hydration by one water molecule induces minimal geometric distortion of the $\mathrm{XHX}^{-}$anions.

These results are consistent with the double hydrogenbonded $C_{2 v}$ anion structures for $\mathrm{BrHBr}^{-} \cdot \mathrm{H}_{2} \mathrm{O}$ and $\mathrm{IHI}^{-} \cdot \mathrm{H}_{2} \mathrm{O}$ in Fig. 4(A) and Table III. These structures have a symmetric hydrogen bond in the $\mathrm{XHX}^{-}$moiety, just as in bare $\mathrm{XHX}^{-}$. The comparison with Table II shows that the individual $\mathrm{H}-\mathrm{X}$ bond lengths are virtually identical in the bare and hydrated anions. The bihalides are slightly bent in the clusters, and this may contribute to the increased width of the peaks in the hydrated vs bare ion PE spectra. Nonetheless, photodetachment from clusters with the $C_{2 v}$ structures will clearly access a very similar region of the neutral $\mathrm{X}+\mathrm{HX}$ surface as does photodetachment of the bare ion. This is illustrated in Fig. 5, where a collinear model potential energy surface for the $\mathrm{Br}$ $+\mathrm{HBr}$ reaction is shown. ${ }^{10}$ The Franck-Condon (FC) region from the vibrational ground state of the bare ion is shaded. The calculated $\mathrm{BrHBr}^{-}$geometry for the $C_{2 v}$ hydrated structure indicated by "@," lies in the center of the bare ion FC region.

The low-lying $(\sim 0.1 \mathrm{eV})$, single hydrogen-bonded $C_{s}$ structure in Fig. 4(B), on the other hand, is not consistent with the PE spectra. In the $C_{s}$ configuration of $\mathrm{BrHBr}^{-} \cdot \mathrm{H}_{2} \mathrm{O}$, for which the calculated structure is given in Table III, the two $\mathrm{H}-\mathrm{Br}$ bond lengths differ by $0.27 \AA$ at the highest level of theory. Thus, as shown in Fig. 5, the $\mathrm{BrHBr}^{-}$geometry, labeled " $\mathbf{\square}$," is shifted significantly from the center of the bare ion FC region and lies more toward the entrance (or exit) valley of the $\mathrm{Br}+\mathrm{HBr}$ potential energy surface. Such a

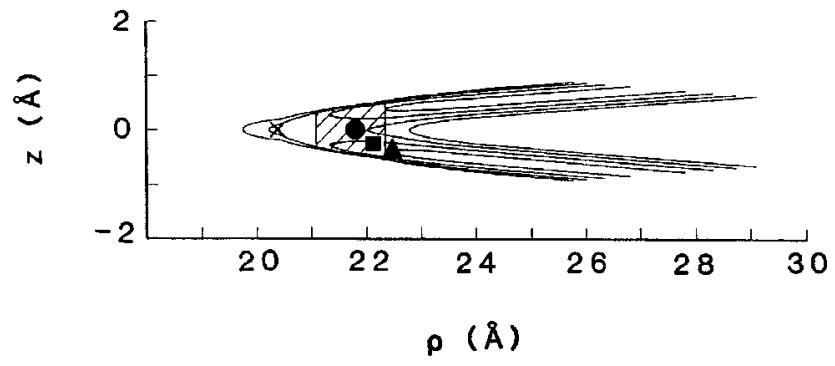

FIG. 5. $\operatorname{BrHBr}^{-}(\boldsymbol{\bullet}), \mathrm{C}_{2 \mathrm{v}} \operatorname{BrHBr}^{-} \bullet\left(\mathrm{H}_{2} \mathrm{O}\right)(\boldsymbol{\bullet}), C_{s} \operatorname{BrHBr}^{-} \cdot\left(\mathrm{H}_{2} \mathrm{O}\right)(\boldsymbol{\square})$, and $\mathrm{BrHBr}^{-} \cdot(\mathrm{HBr})(\boldsymbol{\Delta})$ ground state wave functions superimposed to the $\mathrm{Br}$ $+\mathrm{HBr}$ collinear potential energy surface (Ref. 9).

shift would result in a noticeably higher frequency $\nu_{3}$ progression, because as the two halogen atoms move away from one another, this vibrational mode evolves into the higher frequency vibration of diatomic $\mathrm{HBr}^{10}$ Similar considerations apply to hydrated $\mathrm{IHI}^{-}$. Hence, while the rather small calculated energy differences between the doubly and singly hydrogen-bonded structures might not be convincing evidence that the $C_{2 v}$ structure for the hydrated anions is lower in energy than the $C_{s}$ structure, the experimental PE spectra strongly support this energy ordering.

The $\mathrm{BrHBr}^{-} \cdot \mathrm{H}_{2} \mathrm{O}$ and $\mathrm{IHI}^{-} \cdot \mathrm{H}_{2} \mathrm{O}$ PE spectra are shifted toward lower energy by 0.455 and $0.355 \mathrm{eV}$, respectively, compared to the PE spectra of the bare ions. These "solvent shifts" are similar to but smaller than those seen by Markovich et al. ${ }^{33,34}$ for $\mathrm{Br}^{-} \cdot \mathrm{H}_{2} \mathrm{O}(0.55 \mathrm{eV})$ and $\mathrm{I}^{-} \cdot \mathrm{H}_{2} \mathrm{O}(0.45$ $\mathrm{eV})$. While the solvent shifts reflect the difference in the solvent binding energies to the anion versus neutral cores, ${ }^{32}$ the considerably stronger solvent binding energies in the anions are largely responsible for trends in the solvent shifts. We therefore look to structural differences in the anions to explain the different solvent shifts in hydrated halide versus bihalide $\mathrm{PE}$ spectra. Infrared spectroscopy has shown that $\mathrm{Br}^{-} \cdot \mathrm{H}_{2} \mathrm{O}$ and $\mathrm{I}^{-} \cdot \mathrm{H}_{2} \mathrm{O}$ have a single hydrogen bond between the water and halide anion. ${ }^{19,35,36}$ In the hydrated bihalide anions, there are two hydrogen bonds, but each should be weaker than in $\mathrm{X}^{-} \cdot \mathrm{H}_{2} \mathrm{O}$ because the excess charge is shared equally between the two halogen atoms. While it is not clear whether the net effect from these differing hydrogen bond configurations would result in larger or smaller shifts for the hydrated bihalide anion, the calculated $\mathrm{H}-\mathrm{O}-\mathrm{H}$ bond angle in the hydrated bihalides is $2.5^{\circ}$ smaller than in free water, and this additional "strain energy," which is not present in the $\mathrm{X}^{-} \cdot \mathrm{H}_{2} \mathrm{O}$ clusters, may be the primary cause of the smallest solvent shift in the $\mathrm{XHX}^{-} \cdot \mathrm{H}_{2} \mathrm{O}$ clusters.

\section{B. $\mathrm{XHX}^{-} \cdot(\mathrm{HX})_{n}$}

The PE spectra of $\mathrm{IHI}^{-} \cdot(\mathrm{HI})$ and $\mathrm{BrHBr}^{-} \cdot(\mathrm{HBr})$ show similar characteristics. Compared to the bare ions and the hydrated bihalides, the peaks are broader and their spacing is significantly larger (see Table I), much closer to free $\mathrm{HI}$ and $\mathrm{HBr}$ for $\mathrm{IHI}^{-} \bullet(\mathrm{HI})$ and $\mathrm{BrHBr}^{-} \bullet(\mathrm{HBr})$, respectively. The infrared spectra of $\mathrm{BrHBr}^{-} \cdot(\mathrm{HBr})_{n}(n=0-2)$ and accompanying electronic structure calculations ${ }^{20,21}$ indicate that the addition of $\mathrm{HBr}$ to the $\mathrm{BrHBr}^{-}$complex distorts the symmetry of these clusters, which are better described as a central ha- 


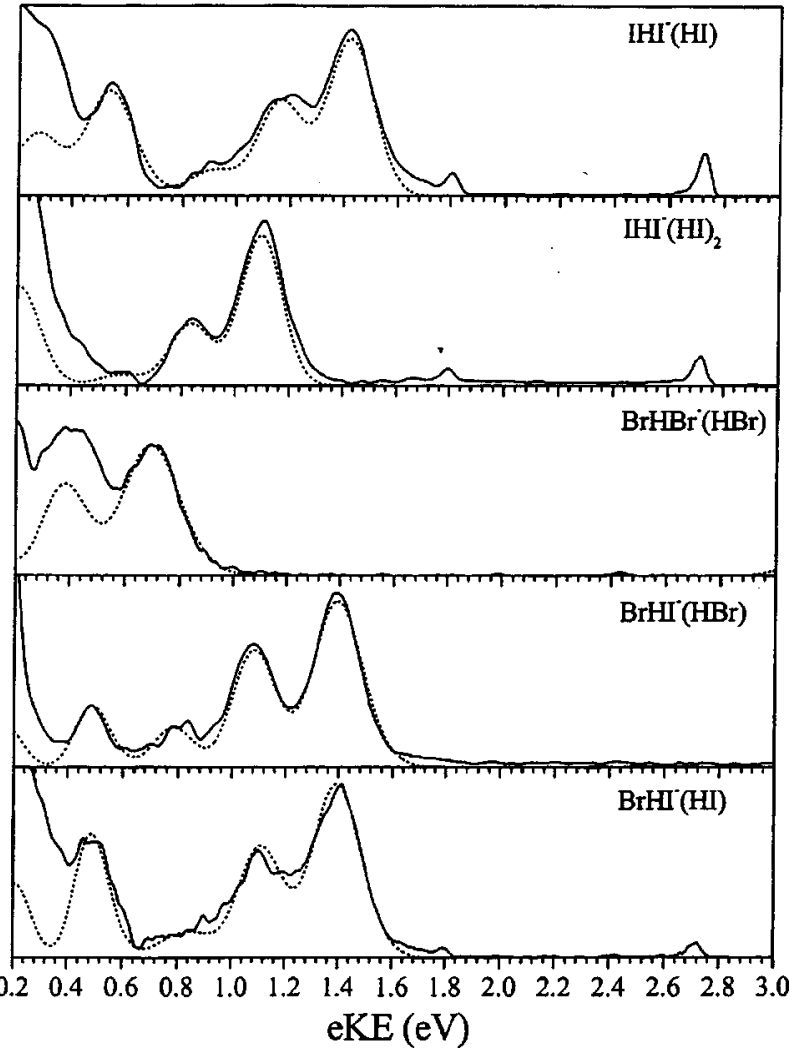

FIG. 6. Franck-Condon simulations (dashed) of the $\mathrm{XHX}^{-} \bullet(\mathrm{HX})_{n}$ and $\mathrm{BrHI}^{-} \bullet(\mathrm{HX})(\mathrm{X}=\mathrm{I}, \mathrm{Br})$ complexes; experimental PE spectra are also shown (solid).

lide ion carrying the most of charge solvated by $\mathrm{HBr}$ molecules. Similar calculated results were obtained in this paper for $\mathrm{IHI}^{-} \cdot(\mathrm{HI})_{n}$ clusters. Both clusters are therefore better described as $\mathrm{X}^{-} \bullet(\mathrm{HX})_{n+1}$ structures for $n>0$.

The PE spectra of these clusters can be interpreted readily in light of the calculated structures. By altering the symmetry of the $\mathrm{XHX}^{-}$complex, a different region of the neutral surface is probed by photodetachment. In effect, the $\mathrm{XHX}^{-}$geometry is even more asymmetrically displaced toward the asymptotic region of the $\mathrm{X}+\mathrm{HX}$ surface [see $\mathrm{BrHBr}^{-} \bullet(\mathrm{HBr})(\boldsymbol{\Lambda})$ in Fig. 5] than when the $C_{s}$ structure of $\mathrm{XHX}^{-} \cdot\left(\mathrm{H}_{2} \mathrm{O}\right)$ is photodetached. We therefore expect the HX bond to be nearly fully formed, but still stretched compared to the equilibrium geometry of diatomic HX. As a result, the PE spectra exhibit a vibrational progression with a frequency quite close to that of diatomic HX. The calculations on $\mathrm{IHI}^{-} \bullet(\mathrm{HI})$ and $\mathrm{IHI}^{-} \bullet(\mathrm{HI})_{2}$ in Table IV show more asymmetry between the $\mathrm{I}^{-} \bullet \bullet \mathrm{H}$ and $\mathrm{HI}$ bond lengths for the larger cluster. The HI bond length is larger than that in diatomic HI (1.626 $\AA$ at the B3LYP/6-311G** level of theory) for both clusters, but closer to the diatomic value for $\mathrm{IHI}^{-} \bullet(\mathrm{HI})_{2}$. One would then expect a shorter progression in the PE spectrum of the larger cluster, in agreement with the experimental spectra in Fig. 1.

In Fig. 6, Franck-Condon simulations of the $\mathrm{XHX}^{-} \bullet(\mathrm{HX})_{n}$ spectra are shown as dashed lines superimposed on the experimental PE spectra. The simulations were performed assuming vibrational activity in a single mode, the totally symmetric linear combination of HX stretches, with the vibrational frequency fixed at the diatomic values. The HX bond length in the neutral was fixed at the diatomic value, and that in the anion was varied to match the length of the experimental progression. The simulated peaks were broadened artificially to match the experimental peak widths, which are due to a combination of activity in unresolved, low frequency vibrations and dissociation on the neutral surface. The best fit $\mathrm{HX}$ bond lengths for $\mathrm{IHI}^{-} \cdot(\mathrm{HI})_{1,2}$ are given as the "experimental" values in Table IV. In both cases, these bond lengths are quite close to the calculated values in the anion clusters.

The $\mathrm{IHI}^{-} \bullet(\mathrm{HI})$ and $\mathrm{BrHBr}^{-} \bullet(\mathrm{HBr}) \mathrm{PE}$ spectra are shifted toward lower eKE by 430 and $625 \mathrm{meV}$, respectively, compared to $\mathrm{IHI}^{-}$and $\mathrm{BrHBr}^{-}$. These shifts are larger than the solvent shifts seen for the corresponding hydrated bihalides. However, the energy shifts with respect to the bare bihalides for $\mathrm{IHI}^{-} \cdot(\mathrm{HI})$ and $\mathrm{BrHBr}^{-} \cdot(\mathrm{HBr})$ are not, strictly speaking, solvent shifts, because addition of an $\mathrm{HI}$ or $\mathrm{HBr}$ to the bihalide results in a significant structural transformation, in contrast to the usual case of anion solvation. They are better interpreted by considering the energy shifts with respect to bare $\mathrm{I}^{-}$or $\mathrm{Br}^{-}, 1.295$ and $1.738 \mathrm{eV}$; these shifts represent the solvent shift for the addition of two HX molecules to the atomic $\mathrm{X}^{-}$halide. The additional shift of $315 \mathrm{meV}$ of the $\mathrm{IHI}^{-} \cdot(\mathrm{HI})_{2}$ spectrum relative to $\mathrm{IHI}^{-} \cdot(\mathrm{HI})$ is a solvent shift in the conventional sense, since the second HI does not induce significant structural changes in the anion.

\section{C. $\mathrm{BrHI}^{-} \cdot \mathrm{HX}$}

The PE spectra of $\mathrm{BrHI}^{-}, \quad \mathrm{BrHI}^{-} \cdot(\mathrm{HBr}), \quad$ and $\mathrm{BrHI}^{-} \cdot(\mathrm{HI})$ in Fig. 3 are quite similar. All show a visible progression with a peak spacing close to $2500 \mathrm{~cm}^{-1}$, but the $\mathrm{BrHI}^{-} \bullet(\mathrm{HI})$ spectrum is more congested than the other two. Since the proton affinity of $\mathrm{Br}^{-}$is about $0.5 \mathrm{eV}$ higher than that of $\mathrm{I}^{-}$, the $\mathrm{BrHI}^{-}$anion can be thought of as $\mathrm{I}^{-} \cdot \mathrm{HBr}$, a result confirmed by recent high level electronic structure calculations by Kaledin et al. ${ }^{37}$ As a result, the Franck-Condon region of anion photodetachment lies in the $\mathrm{I}+\mathrm{HBr}$ product valley, and the photoelectron spectrum is dominated by a vibrational progression in the nascent $\mathrm{HBr}$ product. ${ }^{11}$ Since the anion is already asymmetric, with most of the charge located on the iodine atom, the addition of an additional $\mathrm{HBr}$ or HI molecule should not significantly change the spectral envelope, consistent with the experimental spectra. Hence, the $\mathrm{BrHI}^{-} \bullet(\mathrm{HBr})$ and $\mathrm{BrHI}^{-} \bullet(\mathrm{HI})$ anions are more accurately pictured as $\mathrm{I}^{-} \cdot(\mathrm{HBr})_{2}$ and $\mathrm{I}^{-} \bullet(\mathrm{HBr})(\mathrm{HI})$, respectively. These qualitative considerations are consistent with the electronic structure calculations in Table V.

The length of the vibrational progression in the PE spectrum of bare $\mathrm{BrHI}^{-}$primarily reflects the difference between the (longer) $\mathrm{H}-\mathrm{Br}$ bond length in the anion and in diatomic $\mathrm{HBr}$. The shorter vibrational progression in the $\mathrm{BrHI}^{-} \bullet(\mathrm{HBr})$ spectrum indicate that the analogous bond length changes upon photodetachment are smaller, consistent with interaction between the $\mathrm{I}^{-}$and $\mathrm{HBr}$ becoming smaller with the addition of more solvent molecules. In the $\mathrm{BrHI}^{-} \bullet(\mathrm{HI})$ spectrum, one expects activity in the $\mathrm{HBr}$ and $\mathrm{HI}$ stretches because of solvent interactions with the central $\mathrm{I}^{-}$ion. The 
$\mathrm{HBr}$ and $\mathrm{HI}$ vibrational frequencies are similar but not identical, and this is why the $\mathrm{BrHI}^{-} \bullet(\mathrm{HI})$ spectrum is more congested than the $\mathrm{BrHI}^{-} \bullet(\mathrm{HBr})$ spectrum.

Figure 6 shows reduced dimensionality simulations of the $\mathrm{BrHI}^{-} \cdot(\mathrm{HX})(\mathrm{X}=\mathrm{Br}, \mathrm{I})$ photoelectron spectra, which were performed just like the simulations for the $\mathrm{XHX}^{-}(\mathrm{HX})_{n}$ simulations in the same figure. For $\mathrm{BrHI}^{-} \cdot(\mathrm{HBr})$, only the totally symmetric solvent $\mathrm{HBr}$ stretch mode was assumed to be active, while for $\mathrm{BrHI}^{-} \bullet(\mathrm{HI})$ the $\mathrm{HBr}$ and $\mathrm{HI}$ stretches were allowed to be active. The HX bond lengths in the anion clusters that gave the best fit to the spectra are listed in Table $\mathrm{V}$, where they can be compared to calculated anion geometries. We note that in $\mathrm{BrHI}^{-} \bullet(\mathrm{HI})$, theory and experiment indicate that the $\mathrm{HBr}$ and $\mathrm{HI}$ bond lengths are both longer than in the diatomic species, indicating that both solvent molecules interact strongly with the central $\mathrm{I}^{-}$ion. In addition, both PE spectra undergo a similar solvent shift $(\sim 540$ $\mathrm{meV}$ ) compared to $\mathrm{BrHI}^{-}$, indicating that it makes relatively little difference whether $\mathrm{HBr}$ or $\mathrm{HI}$ is added to $\mathrm{BrHI}^{-}$.

\section{CONCLUSIONS}

The results presented here show how anion PE spectroscopy probes the effects of the polar solvent molecules $\mathrm{H}_{2} \mathrm{O}$, $\mathrm{HI}$, and $\mathrm{HBr}$, on strongly hydrogen-bonded transition state precursor bihalide ions. The structural changes induced by clustering depend on the solvent molecule and on whether the bihalide ion is symmetric or asymmetric. We find that for $\mathrm{XHX}^{-} \cdot \mathrm{H}_{2} \mathrm{O}(\mathrm{X}=\mathrm{Br}, \mathrm{I})$ clusters, the PE spectra retain the vibrational structure of the bare $\mathrm{XHX}^{-} \mathrm{PE}$ spectra, indicating that photodetachment of the singly hydrated clusters probes the $\mathrm{X}+\mathrm{HX}$ transition state region. This result is consistent with a double hydrogen bonded structure in the anion complex, in which the water molecule bonds equally to the two halogens $\mathrm{X}$ in a planar $C_{2 v}$ structure, maintaining the symmetric hydrogen bond characteristic of $\mathrm{XHX}^{-}$anions. We plan to confirm the doubly hydrogen-bonded structure by measurement of the IR spectrum of these ions using the same method used to investigate $\mathrm{BrHBr}^{-}(\mathrm{HBr})_{n}$ clusters. ${ }^{20}$

For the other clusters $\mathrm{XHX}^{-}(\mathrm{M})_{1,2}(\mathrm{M}=\mathrm{HBr}, \mathrm{HI})$, charge localization on one halogen is responsible for breaking the symmetry of the $\mathrm{XHX}^{-}$complex. This is reflected by a large difference in the PE spectra compared to the bare ion. As a result, the anion PE spectrum probes a region of the neutral potential energy surface quite distant from the transition state in the asymptotic region of the $\mathrm{X}+\mathrm{HX}$ surface. The $\mathrm{XHX}^{-} \bullet(\mathrm{M})_{1,2}(\mathrm{M}=\mathrm{HBr}, \mathrm{HI})$ clusters are better described as $\mathrm{X}^{-} \bullet(\mathrm{HX})_{2,3}$. Finally, we observed that the addition of an additional $\mathrm{HBr}$ or $\mathrm{HI}$ molecule to the asymmetric bihalide anion $\mathrm{BrHI}^{-}$induces only small changes in the PE spectrum, because of the already asymmetric structure of $\mathrm{BrHI}^{-}$with its charge localized mostly on the iodine atom.

\section{ACKNOWLEDGMENT}

This research is supported by the Air Force Office of Scientific Research under Grant No. F49620-03-1-0085.
${ }^{1}$ A. H. Zewail, Science 242, 1645 (1988).

${ }^{2}$ P. R. Brooks, Chem. Rev. 88, 407 (1988).

${ }^{3}$ G. C. Schatz, J. Phys. Chem. 94, 6157 (1990).

${ }^{4}$ D. M. Neumark, Acc. Chem. Res. 26, 33 (1993).

${ }^{5}$ D. M. Neumark, PhysChemComm 5, 76 (2002).

${ }^{6}$ S. Leutwyler and J. Bosiger, Faraday Discuss. Chem. Soc. 86, 225 (1988).

${ }^{7}$ B. M. Ladanyi and J. T. Hynes, J. Am. Chem. Soc. 108, 585 (1986).

${ }^{8}$ A. Weaver, R. B. Metz, S. E. Bradforth, and D. M. Neumark, J. Phys. Chem. 92, 5558 (1988).

${ }^{9}$ I. M. Waller, T. N. Kitsopoulos, and D. M. Neumark, J. Phys. Chem. 94, 2240 (1990)

${ }^{10}$ R. B. Metz, A. Weaver, S. E. Bradforth, T. N. Kitsopoulos, and D. M. Neumark, J. Phys. Chem. 94, 1377 (1990).

${ }^{11}$ S. E. Bradforth, A. Weaver, D. W. Arnold, R. B. Metz, and D. M. Neumark, J. Chem. Phys. 92, 7205 (1990).

${ }^{12}$ D. E. Manolopoulos, K. Stark, H. J. Werner, D. W. Arnold, S. E. Bradforth, and D. M. Neumark, Science 262, 1852 (1993).

${ }^{13}$ S. E. Bradforth, D. W. Arnold, D. M. Neumark, and D. E. Manolopoulos, J. Chem. Phys. 99, 6345 (1993).

${ }^{14}$ E. Debeer, E. H. Kim, D. M. Neumark, R. F. Gunion, and W. C. Lineberger, J. Phys. Chem. 99, 13627 (1995).

${ }^{15}$ D. W. Arnold, Ph.D. dissertation, University of California, Berkeley, 1994.

${ }^{16}$ D. M. Neumark, in Advances in Molecular Vibrations and Collision Dynamics, edited by J. M. Brauman and M. A. Ratner (JAI, Greenwich, 1991), Vol. 1A, p. 165.

${ }^{17}$ Z. Liu, H. Gomez, and D. M. Neumark, Chem. Phys. Lett. 332, 65 (2000).

${ }^{18}$ Z. Liu, H. Gomez, and D. M. Neumark, Faraday Discuss. 118, 221 (2001).

${ }^{19}$ C. G. Bailey, J. Kim, C. E. H. Dessent, and M. A. Johnson, Chem. Phys. Lett. 269, 122 (1997).

${ }^{20}$ N. L. Pivonka, C. Kaposta, G. V. Helden, G. Meijer, L. Woste, D. M. Neumark, and K. R. Asmis, J. Chem. Phys. 117, 6493 (2002).

${ }^{21}$ N. L. Pivonka, C. Kaposta, M. Brummer, G. v. Helden, G. Meijer, L. Woste, D. M. Neumark, and K. R. Asmis, J. Chem. Phys. 118, 5275 (2003).

${ }^{22}$ C. Xu, G. R. Burton, T. R. Taylor, and D. M. Neumark, J. Chem. Phys. 107, 3428 (1997)

${ }^{23}$ R. B. Metz, S. E. Bradforth, and D. M. Neumark, in Adv. Chem. Phys., edited by I. Prigogine and S. A. Rice (Wiley, New York, 1992), Vol. 91, pp. $1-61$.

${ }^{24}$ H. Hotop and W. C. Lineberger, J. Phys. Chem. Ref. Data 14, 731 (1985).

${ }^{25}$ A. D. Becke, J. Chem. Phys. 98, 1372 (1993).

${ }^{26}$ C. Lee, W. Yang, and R. G. Parr, Phys. Rev. B 37, 785 (1988).

${ }^{27}$ M. J. Frisch et al., GAUSSIAN 98, Gaussian, Inc., Pittsburgh, PA, 1998.

${ }^{28}$ G. P. Li, B. Reinhart, and I. P. Hamilton, J. Chem. Phys. 115, 5883 (2001).

${ }^{29}$ E. A. Woronowicz, W. H. Robertson, G. H. Weddle, M. A. Johnson, E. M. Myshakin, and K. D. Jordan, J. Phys. Chem. A 106, 7086 (2002).

${ }^{30}$ I. G. Shenderovich et al., Ber. Bunsenges. Phys. Chem. 102, 422 (1998).

${ }^{31}$ S. A. Perera and R. J. Bartlett, J. Am. Chem. Soc. 122, 1231 (2000).

${ }^{32}$ A. W. Castleman, Jr. and K. H. Bowen, Jr., J. Phys. Chem. 100, 12911 (1996).

${ }^{33}$ G. Markovich, R. Giniger, M. Levin, and O. Cheshnovsky, J. Chem. Phys. 95, 9416 (1991).

${ }^{34}$ G. Markovich, S. Pollack, R. Giniger, and O. Cheshnovsky, J. Chem. Phys. 101, 9344 (1994)

${ }^{35}$ M. S. Johnson, K. T. Kuwata, C. K. Wong, and M. Okumura, Chem. Phys. Lett. 260, 551 (1996).

${ }^{36}$ P. Ayotte, C. G. Bailey, G. H. Weddle, and M. A. Johnson, J. Phys. Chem. A 102, 3067 (1998).

${ }^{37}$ A. Kaledin, S. Skokov, J. M. Bowman, and K. Morokuma, J. Chem. Phys. 113, 9479 (2000).

${ }^{38}$ G. Herzberg, Electronic Spectra and Electronic Structure of Polyatomic Molecules (Van Nostrand, New York, 1966).

${ }^{39}$ G. Herzberg, Spectra of Diatomic Molecules (Van Nostrand, New York, 1950). 
The Journal of Chemical Physics is copyrighted by the American Institute of Physics (AIP). Redistribution of journal material is subject to the AIP online journal license and/or AIP copyright. For more information, see http:/ojps.aip.org/jcpo/jcpcr/jsp Copyright of Journal of Chemical Physics is the property of American Institute of Physics and its content may not be copied or emailed to multiple sites or posted to a listserv without the copyright holder's express written permission. However, users may print, download, or email articles for individual use. 
The Journal of Chemical Physics is copyrighted by the American Institute of Physics (AIP). Redistribution of journal material is subject to the AIP online journal license and/or AIP copyright. For more information, see http://ojps.aip.org/jcpo/jcper/jsp 